\title{
Residential Setting and Parent-Adolescent Relationships During the College Years
}

\author{
Constance Flanagan, ${ }^{1}$ John Schulenberg, ${ }^{2}$ and Andrew Fuligni ${ }^{3}$
}

Received May 7, 1992; accepted October 1, 1992

The relationship of residential setting (living with parents $v$ s. living away from home while attending college) and gender with late adolescents' perceptions of their relationships with parents was examined. Four hundred four undergraduates students (mean age $=20$ years, 4 months) from two midwestern universities completed surveys. Two hundred four subjects lived with their parents and commuted to school, and 200 lived away at college. Controlling for student's age, parents' education, and financial and family considerations as factors in the choice of a college, living away was associated with greater independence, support, and mutual respect between parents and adolescents. In contrast, students who lived at home felt parents underestimated their maturity, and reported more conflict and avoidance in their relationships with parents. Regardless of residential setting, women reported more mutuality and support in their relationships with parents than men. The results suggest the importance of considering contextual issues during the transition to adulthood.

This research was supported by a Campus Grant to the first author from the University of Michigan-Dearborn.

${ }^{1}$ Assistant Professor, Behavioral Sciences, University of Michigan-Dearborn, Dearborn, Michigan 48128. Received Ph.D. in developmental psychology from the University of Michigan. Research interests include family relationships, cross-cultural studies, and political development in adolescence and young adulthood. To whom correspondence should be addressed at 1125 University Mall, University of Michigan-Dearborn, Dearborn, Michigan 48128 .

${ }^{2}$ Assistant Research Scientist, Institute for Social Research, University of Michigan, Ann Arbor, Michigan 48106-1248. Received Ph.D. in human development and family studies from Penn State University. Research interests include competence during the transition to young adulthood, career development, drug and alcohol use.

${ }^{3}$ Ph.D. candidate, Developmental Psychology, Mason Hall, University of Michigan, Ann Arbor, Michigan 48106. Research interests include adolescents' relationships with parents and peers and cross-cultural studies. 


\section{INTRODUCTION}

The growth in independence during the adolescent years is accompanied by an expectation of increasing symmetry in the parent-child relationship (White et al., 1983; Youniss, 1983). Although parents continue to figure prominently as a source of affection and instrumental aid (Lempers and Clark-Lempers, 1992), adolescents increasingly make their own decisions and parents' authority over those decisions declines. The challenge for both parent and adolescent is to redefine their relationship and nurture new connections. Despite the large numbers of psychological studies conducted with college students, relationships with parents during the transition from adolescence to adulthood has been an understudied topic (Hill and Holmbeck, 1986; Paul, 1992), a lack of attention that may be due, in part, to assumptions about norms at this time. Leaving home, both psychologically and physically, is the normal expectation for a successful transition to adulthood (Levinson, 1986; Gould, 1978). This expectation is so pervasive that, as Bell and Bell (1983) observe, "Texts on adolescent psychology leave one with the impression that the major function of the family during this developmental phase is to give the adolescent someone to leave" (p. 27).

The transition from high school to college is a significant marker in the life course, and there has been a good deal of interest in how students who go away to school cope with separation from their families and adjustment to college (Berman and Sperling, 1991; Cantor et al., 1987; Compas et al., 1986; Hamilton and Fagot, 1988; Kidwell, 1992). However, many late adolescents do not leave home when they go to college. Analyses of census data indicate an increase in the number of people in their $20 \mathrm{~s}$ who continue to reside with their parents or who have moved back home after a period of separation (Clemens and Axelson, 1985; Glick and Lin, 1986; Vobejda, 1991). If leaving home is not the norm for large numbers of late adolescents, then more attention should be paid to the role of residential setting in various psychosocial issues at this time. The present study was undertaken to describe the role that physical separation may play in parent-adolescent relationships. Our primary question was, In what ways might relationships with one's parents differ for college students who move away compared to those who continue living at home?

In the late 1970s, Sullivan and Sullivan (1980) conducted a unique study testing the effects of residential setting (boarding at college or commuting from home) on several dimensions of young men's relationships with their parents. Reports of independence, affection, and communication with parents were gathered during the senior year of high school and the first year of college. Although there were no differences between groups 
on any of the measures in high school, the group who went away to college reported a significant increase in affection for parents. Leaving home did not significantly increase independence or communication. However, there was an interaction of residential status (boarding at college/living at home) with time (high school/college) due to a simultaneous increase on these dimensions for the home leavers and a decrease for those who remained at home. In sum, during the first year of college, men who lived away reported a greater sense of independence and better communication with their parents than their peers who lived at home, whereas there were no differences between groups prior to college.

The Sullivans' work was ground-breaking in that it contextualized the question of relationships with parents during the college years. Nonetheless, in the last decade little attention has been paid to the role of residential context, which is surprising considering the trend of youth remaining at home for longer periods.

The present study attempts to fill this gap in the literature by building on the Sullivans' work in three important ways. First, we sampled a broader array of perceptions to tap the quality of late adolescents' relationships with their parents. For example, we wanted to distinguish some of the dimensions of communication that were combined in the Sullivans' measure (i.e., respect, avoidance) as well as tap adolescents' perceptions of tensions and a lack of symmetry in the relationship. Second, the mean age of the subjects in the Sullivans' study was 17.8 years (range of 17-18) and no women were included. In contrast, the sample for the present study has a higher mean age and broader age range. The inclusion of women in this study permits us to consider variation in relationships with parents as a function of the late adolescent's sex as well as to assess whether residential status is relevant to late adolescents' relationships with parents, regardless of sex. Finally, because the data for the Sullivans' study were collected in 1976, we felt it was important to examine the transition to early adulthood in light of the changing demographics of the last fifteen years.

With respect to possible gender differences, both theoretical and empirical work emphasize the importance of attachments in women's psychosocial development (Frank et al., 1988; Franz and White, 1985). Frank et al. (1988) found that late adolescent women were more likely than men to feel connected (in terms of empathy, communication, and closeness) to their parents, although they found no differences in women's and men's feelings of competence (i.e., independence and decision making) with respect to their parents. Others have noted that parental attachments are a central factor in women's ability to form a "dream" in Levinson's sense of envisioning a purposeful future and establishing a stable life structure (Stewart, 1977, cited in Roberts and Newton, 1987). In short, women's ego develop- 
ment may be more strongly related to their affective ties to parents than is men's (White et al., 1983).

Admittedly, attempting to measure relationships with parents during the transition to adulthood is an unwieldy task. Others (e.g., Frank et al., 1988; Paul, 1992; White et al., 1983) have chosen a structured interview approach in which some of the complexities of this topic can be thoroughly explored. But there are inevitable methodological trade-offs with interview methods that argue for additional measurement strategies. Although several inventories exist in the literature, we felt there was a need for a closedended measure that would focus on individuation as a relational issue between adolescents and parents (Grotevant and Cooper, 1986). A secondary purpose of the study, then, was to present evidence regarding the preliminary self-report measure.

In assessing late adolescents' relationships with their parents, we had two objectives. The first was to identify adolescents' perceptions of a relational style that facilitated individuation and encouraged independence within the context of continued connection to parents (Cooper et al., 1983; DeSantis and O'Brien, 1992; Grotevant and Cooper, 1986; Hill and Holmbeck, 1986; Ryan and Lynch, 1989). In specifying these constructs for 1826-year-olds, we targeted three aspects that have been the focus of past research: Mutuality, which taps a peer-like communication style in which parent and child respect one another's unique opinions; support, in particular the sense that parents could be relied on when needed; independence, a sense of self-governance and parental encouragement of autonomy (Grotevant and Cooper, 1985; Lempers and Clark-Lempers, 1992; Sullivan and Sullivan, 1980; White et al., 1983; Youniss and Smollar, 1985).

The second objective was to tap late adolescents' perceptions that their parents were unresponsive to the maturational demands of the transition to adulthood, that there was a lack of symmetry in their relationship, and that parents and adolescents avoided rather than discussed and negotiated differences of opinion (Montemayor and Hanson, 1985).

In summary, we had two general hypotheses. First, we expected that living away from home would be associated with a relational style that facilitated independence in the context of affection and support. Conversely, we expected that students who lived at home would feel their independence strivings were constrained by parents who minimized the responsibilities involved in the transition to adulthood. Likewise, levels of conflict and problems in negotiating differences of opinion were hypothesized to be higher when students lived at home. Finally, in line with other work on gender differences, women were expected to report closer ties to their parents than men, regardless of residential setting (i.e., no residence by gender interactions). 


\section{METHOD}

\section{Sample}

The sample of 404 undergraduate students was recruited from two universities in the midwest. These universities were quite comparable settings. Both were state-supported institutions that focused on undergraduate education. Tuition was quite similar at the two settings and the student body at each institution was a mix of urban and suburban in-state students. Two hundred and four subjects lived with their parents and commuted to school, and 200 lived away at college. Mean age of the participants was 20 years, 4 months, range of 18-26 years old. Thirty-eight percent of the sample was male. The breakdown by class level was $23 \%$ freshmen, $27 \%$ sophomores, $25 \%$ juniors, and $25 \%$ seniors. Eighty-six percent of the sample was Caucasian, 3.7\% African-American, 3\% Asian-American, 3\% Arab-American, and $4.3 \%$ were other minorities. On average, the mothers of the sample participants had some technical training or college classes beyond high school and the fathers had completed two years of college.

\section{Procedure}

The study was described to students in undergraduate classes as a broad survey of issues that concern late adolescents, including relationships with parents. Students who agreed to participate were asked to take the survey with them, to complete it outside of class, and to return it during the next class period.

\section{Independent Measures}

\section{Residential Status}

A two-level categorical variable for residential status (at home; away from home) was created based on students' reports of their current living arrangements while in school. Living with parents or in an extended family were coded as residing "at home"; living in a dormitory, alone, or with friends in an apartment or house, or in a sorority or fraternity were coded in the "away from home" category. It should be noted that residential status varied considerably across the two universities. One of the universities was primarily a "commuter" campus, and $90 \%$ of the students in the sample from this campus lived at home. Most of the students on this campus who did not reside with their parents were foreign students and were excluded 
from the analyses. The other campus was primarily an "in-residence" campus, with less than $8 \%$ of the students living at home.

\section{Parents' Education}

Respondents were asked to report the highest level of education that their mothers and fathers attained. Maternal and paternal education were each measured on a 1 (did not finish high school) to 7 (graduate or professional degree) scale.

\section{Subjects' Age}

Subjects were asked to indicate their age on a scale where $1=18$ or under: $2=19 ; 3=20$, etc.

\section{Family and Financial Considerations}

Because this was a cross-sectional study we had no assessment of adolescents' relationship with their parents prior to entering college. In order to control for selection factors associated with residential status, we asked the students three items about the importance of family considerations and two items about the importance of financial considerations in their decision about where to attend college. The three family considerations items arranged on a Likert-type scale (1: not at all important; 5: very important), were the responsibilities they had at home, the strong emotional ties they had to friends and family, and the fact that their parents did not want them to go away to school. The two financial considerations items arranged on the same scale were how expensive college would be and whether they could afford to live away from home.

\section{Dependent Measures}

\section{Late Adolescents' Relationships with Parents (LARP) Scale}

Derived in part from the conceptualizations of the parent-adolescent relationship during the transition to young adulthood cited previously, and drawing some direction from Sullivan and Sullivan's (1980) Parent Adolescent Relationship questionnaire (PARQ), and O'Brien et al.'s (1988) Adolescent Individuation Measure (AIM), a preliminary set of 48 items was developed to capture several dimensions of independence, communication, 
affection, and tensions in the interactions of late adolescents and their parents.

Based on a series of expert judgments, reliability and validity considerations, and exploratory factor analyses, the 48 items were reduced to 26 . These 26 items, which are presented in Appendix A, represent our preliminary version of the LARP. Seven of the items were adapted from existing measures ( 4 from the PARQ, and 3 from the AIM), and the remaining 19 items were developed for this study. Possible responses to each item are arranged along a 7-point Likert-type scale (1: strongly disagree; 7: strongly agree).

In a final exploratory factor analysis of the 26 items, the number of factors was determined to be six based on the scree test (Cattell, 1966) and the number of eigenvalues $\geqq 1.00$. Using an oblique rotation, the factors approximated simple structure (i.e., in general, each item had a high loading for one factor and low loadings for all other factors; cf. Gorsuch, 1983). The factor loadings, unique variances, and factor intercorrelations are presented in Table I. The six factors are as follows: Mutuality (high scores indicate a confidante relationship with parents and mutual respect for differences of opinion); Enabling Independence (high scores reflect selfdetermination in the context of parental encouragement); Support (affection and the perception that parents can be relied on, if needed); Rejection (a tendency to reject one's parents as role models); Avoidance (an inability to compromise or resolve differences of opinion); and Parents' Underestimation of Maturity Demands (the perception that parents minimize the demands of the adolescent to adult transition).

The first three factors represent an affectionate relationship in which the adolescent's independence is encouraged. As indicated in Table I, these three factors are all positively intercorrelated. The remaining three factors represent a parenting style that is less supportive of the adolescent's independence and a more tense parent-child relationship. These are also positively intercorrelated, and each is negatively correlated with the first three factors. It is important to note that the factors were found to be invariant with respect to gender and residential status. That is, in separate analyses, the same configurations of item and factors were found for females and males, and for those living at home and those living away from home.

Based on the factor analysis, six subscales were formed. Because the factor solution was a good approximation of simple structure, and because the values of the factor loadings were fairly similar on each factor, the most straightforward way to form subscale scores was to take the unweighted mean of the items that were most highly correlated with each factor (cf. Gorsuch, 1983). Note that those items with underlined loadings (in Table I) were included in the given subscale, and 2 items (on the Sup- 


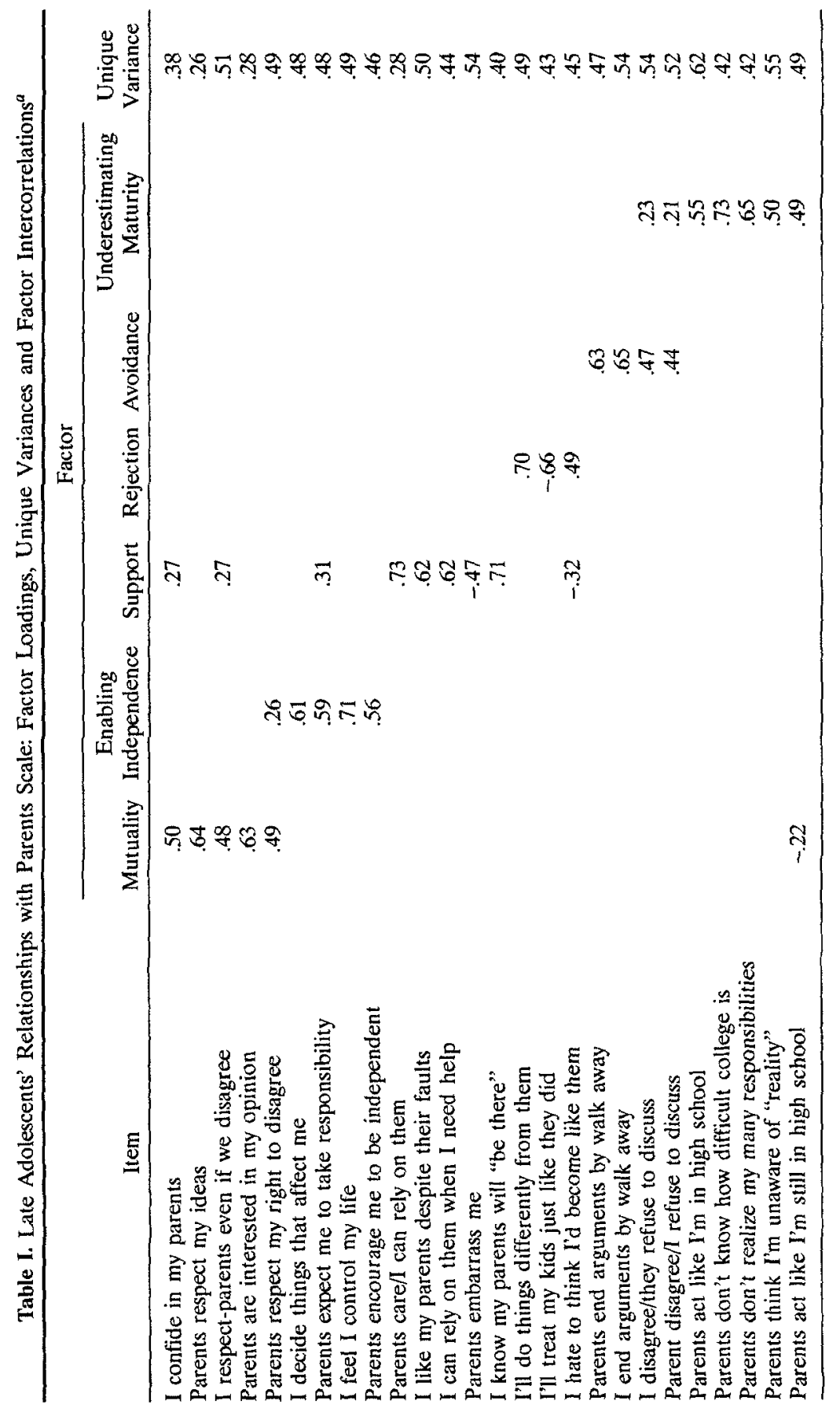




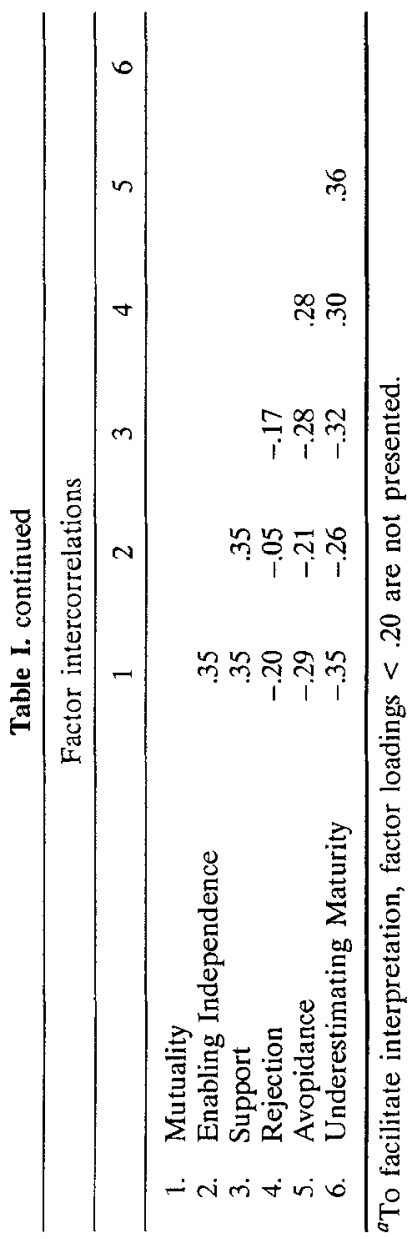


port and Rejection of Parents subscales) were reverse coded before the subscale was constructed. The number of items per subscale ranged from 3 to 5. Cronbach's alpha coefficients for each subscale were as follows: .89 for Mutuality; .80 for Enabling Independence; .85 for Support; .73 for Rejection; .78 for Avoidance; and .82 for Parental Underestimation of Maturity Demands.

\section{Conflict With Parents During Different Periods of the Year}

Subjects were asked three questions on a 5-point Likert format scale about levels of conflict with parents. Two of these questions asked how often they had minor or major arguments with their parents during the school year and the third asked how much conflict occurred between them and their parents during semester break when they were living at home. Frequency of major arguments was correlated .64 and .50 , respectively, with frequency of minor arguments and conflict between semesters; frequency of minor arguments was positively correlated with conflict between semesters $(r=.33)$.

\section{RESULTS}

Analysis of variance indicated a significant relationship between residential setting and both maternal $(F[1,402]=9.43, p<.01)$ and paternal

Table II. Correlations Between Late Adolescents' Age and Parent's Education with Late Adolescents' Relationships with Parents

\begin{tabular}{lcc}
\hline & $\begin{array}{c}\text { Late } \\
\text { adolescents' age }\end{array}$ & $\begin{array}{c}\text { Parents' } \\
\text { education }\end{array}$ \\
\hline Aspect of relationship & $.15^{b}$ & $.09^{a}$ \\
$\quad$ Mutuality & $.15^{b}$ & .05 \\
Enabling Independence & .00 & .01 \\
Support & .03 & $-.09^{a}$ \\
Rejection of parents & -.08 & $-.16^{b}$ \\
Avoidance & $-.10^{a}$ & $-.22^{c}$ \\
Underestimating Maturity & & \\
Conflict with parents & $-.13^{b}$ & -.04 \\
Minor disagreements & $-.10^{a}$ & -.02 \\
Major disagreements & $-.09^{a}$ & .06 \\
Conflict between semesters & & \\
\hline${ }_{p}<.05$. & & \\
${ }_{p} p<.01$. & & \\
$c_{p}<.001$. & &
\end{tabular}


Table III. Effects of Residential Setting on Late Adolescents' Relationships with Parents

\begin{tabular}{|c|c|c|c|c|c|}
\hline & \multicolumn{2}{|c|}{ Live away } & \multicolumn{2}{|c|}{ Live at home } & \multirow[b]{2}{*}{$F(1,398)$} \\
\hline & $M$ & $(S D)$ & $M$ & $(S D)$ & \\
\hline \multicolumn{6}{|l|}{ Aspect of relationship } \\
\hline $\begin{array}{l}\text { Mutuality } \\
\text { Enabling Independence } \\
\text { Support } \\
\text { Rejection of parents } \\
\text { Avoidance } \\
\text { Underestimating Maturity }\end{array}$ & $\begin{array}{l}5.28 \\
5.91 \\
6.21 \\
4.14 \\
2.56 \\
2.86\end{array}$ & $\begin{array}{l}(1.13) \\
(0.90) \\
(1.05) \\
(1.47) \\
(1.28) \\
(1.31)\end{array}$ & $\begin{array}{l}4.76 \\
5.50 \\
5.95 \\
4.58 \\
3.03 \\
3.45\end{array}$ & $\begin{array}{l}(1.23) \\
(1.11) \\
(1.05) \\
(1.37) \\
(1.33) \\
(1.45)\end{array}$ & $\begin{array}{r}15.47^{c} \\
9.14^{b} \\
6.70^{a} \\
12.43^{b} \\
7.41^{b} \\
7.22^{b}\end{array}$ \\
\hline \multicolumn{6}{|l|}{ Conflict with parents } \\
\hline $\begin{array}{l}\text { Minor disagreements } \\
\text { Major disagreements } \\
\text { Conflict between semesters }\end{array}$ & $\begin{array}{l}2.53 \\
1.75 \\
2.20\end{array}$ & $\begin{array}{l}(0.77) \\
(0.82) \\
(0.90)\end{array}$ & $\begin{array}{l}3.00 \\
2.15 \\
2.29\end{array}$ & $\begin{array}{l}(0.90) \\
(0.84) \\
(0.92)\end{array}$ & $\begin{array}{c}23.72^{c} \\
17.02^{c} \\
0.69\end{array}$ \\
\hline
\end{tabular}

${ }^{a} p<.01$.

${ }^{b} p<.001$.

$c_{p}<.0001$.

$(F[1,400]=6.36, p<.05)$ education. Mother's $(M=3.52, S D=1.45$ vs. $M=3.09, S D=1.39)$ and father's $(M=3.97, S D=1.66$ vs. $M=3.56$, $S D=1.57$ ) education were both higher among students who lived away compared to those who lived at home. In addition, there was a significant association of age with residential setting, $(F[1,403]=14.12, p<.001)$. On average, students who lived away at college were somewhat older $(M$ $=20.66, S D=1.45)$ than those who resided with their parents $(M=20.08$, $S D=1.63)$. There was no significant relationship between residential setting and student's grade point average. Residential setting was related to reports that family $(F[1,403]=36.44, p<.001)$ and financial $(F[1,403]$ $=5.84, p<.01)$ considerations each played a role in the choice of a college. Students who lived at home had higher mean levels of family considerations (home: $M=2.73, S D=0.95$; away: $M=2.19, S D=0.82$ ) and financial considerations (home: $M=3.53, S D=1.28$; away: $M=3.22, S D=1.21$ ) compared to those who lived away.

Adolescent's age and parents' education were found to be related to some aspects of relationships with parents, though not very strongly. As shown in Table II, age was positively correlated with mutuality and independence and negatively correlated with parental underestimation of maturity demands and indicators of conflict. In addition, students of more highly educated parents reported more mutuality and less rejection, avoidance, and underestimation of maturity demands. 
To test for the effect of residential status and gender on students' relationships with their parents, a 2 (residential status) by 2 (sex of respondent) multivariate analysis of covariance (MANCOVA) was performed, with student's age, parents' average education, financial, and family considerations as covariates. A single MANCOVA was performed instead of a separate analysis of covariance for each aspect of students' relationships with their parents in order to control for the shared variance between the outcome measures, thereby minimizing the occurrence of duplicate and redundant significant results.

The omnibus tests of the MANCOVA were first performed, followed by univariate tests of each aspect of young adults' relationships with their parents. Overall, the results of the MANCOVA indicated that residential status had a significant effect on college students' perceptions of relationships with their parents, $(F[9,388]=3.66, p<.001)$, even after controlling for parents' education, the importance of family and financial considerations for selecting college, gender, and the shared variance between the outcome measures. Gender also had a significant overall effect $(F[9,388]$ $=4.40, p<.001$ ), but the interaction effect of residential status with gender was not significant $(F[9,388]=0.50$, ns $)$.

Controlling for students' age, parents' education, financial and family-related considerations for attending college, univariate tests revealed significant effects of residential status on all aspects of parent-adolescent relationships (Table III). Students who lived away from home while attend-

Table IV. Effects of Gender on Late Adolescents' Relationships with Parents

\begin{tabular}{lccccccc}
\hline & \multicolumn{3}{c}{ Male } & & \multicolumn{2}{c}{ Female } & \\
\cline { 2 - 3 } & $M$ & $(S D)$ & & $M$ & $(S D)$ & & $F(1,398)$ \\
\hline Aspect of relationship & & & & & & \\
$\quad$ Mutuality & 4.74 & $(1.21)$ & & 5.16 & $(1.19)$ & $8.44^{a}$ \\
Enabling Independence & 5.59 & $(0.94)$ & & 5.74 & $(1.08)$ & 1.39 \\
Support & 5.72 & $(1.15)$ & & 6.28 & $(0.95)$ & $24.98^{b}$ \\
Rejection of parents & 4.46 & $(1.35)$ & & 4.29 & $(1.48)$ & 0.52 \\
Avoidance & 2.89 & $(1.21)$ & & 2.76 & $(1.39)$ & 0.37 \\
Underestimating Maturity & 3.32 & $(1.35)$ & & 3.08 & $(1.46)$ & 2.02 \\
Conflict with parents & & & & & & \\
Minor disagreements & 2.77 & $(0.85)$ & & 2.78 & $(0.88)$ & 0.58 \\
Major disagreements & 1.94 & $(0.81)$ & & 1.97 & $(0.87)$ & 0.77 \\
Conflict between semesters & 2.25 & $(0.88)$ & 2.24 & $(0.92)$ & 0.01 \\
\hline
\end{tabular}

${ }_{a p}<.01$
$b_{p}<.001$ 
ing college reported more mutuality, independence, and support, whereas those who lived at home reported more avoidant communication, rejection of parents as role models, and a greater tendency on the part of parents to underestimate the maturity demands of this stage on their sons and daughters.

Finally, as shown in Table III, residential status was also significantly associated with both major and minor conflicts, but not with levels of conflict between semesters. As expected, students who lived at home reported more conflict than those who went away, but these differences disappeared between semesters when all students were living at home.

Univariate tests of the effect of gender revealed significant differences in support and mutuality, but not in the other subscales, nor in the conflict items (see Table IV). As expected, females reported more support and mutuality than did males.

\section{DISCUSSION}

The process of individuation intensifies during the high school years as adolescents typically spend more time away from their families. This experience of separation gives them an opportunity for privacy, a chance to explore their own ideas, and to control how much parents know about them (Youniss and Smollar, 1985). If this taste of separation and independence is typical in high school, then the normal expectation for the college years would be an increase in privacy, independence, and freedom from parental monitoring. The data from this study suggest that the redefinition of relations with parents may be more problematic when parents and their late adolescent children are living under the same roof.

Not only did students who lived at home enjoy less independence and report lower levels of mutuality in their relationship, they were more likely to perceive negative aspects of the relationship. Specifically, they felt parents were oblivious to the responsibilities and demands they faced in college, and treated them as if they were still in high school. When adolescents and parents lived together, they tended to deal with their disagreements by avoiding one another rather than attempting to discuss and resolve differences of opinion. Conflicts with parents in terms of both minor hassles and major disagreements were exacerbated by living together. Even students who resided at college said they had more conflict with their parents during semester breaks when they lived at home.

The pattern of results suggests that physical separation as well as elements of the "nonhome" residential setting may have a bearing both on the process of individuation and on the parent-child relationship. Living 
away from home, typically removed from direct "older adult" monitoring, marks a transition point in an adolescent's development. Leaving home to attend college carries some significance in society generally such that the parents and their adolescent children clearly sense that a meaningful transition in their relationship is occurring. Furthermore, living on one's own forces the adolescent to make decisions without daily input from parents and, at the same time, allows him/her to control how much parents will know about those decisions. In such a context one's relationship with parents may be viewed in a more positive light. Consistent with the work of Offer and Offer (1975), who found that parents reported better relationships with their late adolescent sons when the sons were living away, these results suggest that absence may be related to more positive perceptions on the part of the late adolescent as well.

Although moving away appears to facilitate certain aspects of the individuation process, the relational picture presented in these data was generally positive, regardless of residential setting. Specifically, the mean levels of independence, mutuality, and support were relatively high, whereas conflict, avoidance, and the perception that parents trivialized the demands of young adulthood tended to be low. The one exception was for rejection of parents as role models. This variable was positively correlated with avoidance and underestimation of maturity demands; yet a comparison of the sample means suggests that rejecting parents as role models is moderately endorsed by adolescents in both residential settings. Rejecting parents as role models is a form of deidealization, a recognition that parents are fallible, that their shortcomings can be objectively assessed (Frank et al., 1990). As such, it may be a necessary part of separating from the family and becoming increasingly self-directed (Hill and Holmbeck, 1986).

The positive correlations of mutuality, support, and independence warrant some discussion. Contemporary theories of adult development have emphasized that attachment and individuation are complementary developmental processes, both essential to mature relationships (Franz and White, 1985; Moore, 1987; Paul, 1992; White et al., 1987). That mutuality and support were positively correlated with independence corroborates other work showing that a sense of autonomy in adolescence can be fostered in an atmosphere of affection and continued connection to one's parents (Campbell et al., 1984; Grotevant and Cooper, 1986; Steinberg and Lamborn, 1992; Youniss and Smollar, 1985).

We do not want to conclude from these results that leaving home has positive and staying home negative implications for parent-adolescent relationships. As already noted, perceptions of conflict and avoidance were low, regardless of residential setting. Rather, the results point to the need 
to consider different relational paths during the transition to young adulthood (Paul, 1992). Leaving home to attend college may minimize the confrontational aspects of separating from parents, make their flaws pale in the light of new opportunities for self-governance, and even help college students appreciate what parents mean to them. In contrast, for the student who lives at home, the desire for detachment may be strengthened by physical proximity. Conflict may play a key role in the process of individuation in this context if one is regularly standing up for him/herself in opposition to parents (Blos, 1979; Shantz and Hobart, 1989).

Consistent with past work in which women reported greater empathy, communication, and closeness with parents than men (Campbell et al., 1984; Frank et al., 1988), these findings also support the greater relational aspects of women's psychosocial development in late adolescence and early adulthood. Furthermore, as this and other studies have shown, there is no apparent cost of these affective ties to women's independence.

Of course, the findings must be placed within the limitations of this study. Although the study has addressed the need to frame parent-adolescent relationships within the larger social context where they are embedded (Demo, 1991), the cross-sectional design prohibits any tests regarding causal relationships. The student's residential status could be the result rather than the cause of the pattern of observed relationships. While this alternative interpretation is possible, we consider it unlikely for several reasons. First, financial considerations are likely to be the overarching factor in determining college decisions. In this sample, students who resided at home were more likely than those who went away to say that financial considerations were an important part of their college decision. Family-related considerations were also a bigger factor in the choice of college for students who stayed at home compared to those who left home. However, the significant association of residential status with the outcomes remained after controlling for these factors. Furthermore, although preexisting relationships may have played a role in the decision to leave or stay at home, it seems more likely that adolescents would attempt to distance themselves from relationships characterized by conflict and tension. Based on our findings and given a contextually sensitive conceptualization of developmental transitions, attributing all of the residential differences to preexisting group differences would be an error.

Besides the design limitations, the fact that this sample was drawn from a university population restricts our ability to generalize the results to that large segment of American youth who do not attend college (The Forgotten Half, 1988). Indeed, the significant loss of jobs in the manufacturing sector has dealt the worst financial blow to these youth and has delayed their time line for moving out of their parents' homes. In addition, 
including parents in future studies would provide a richer understanding of how relationships are renegotiated during the transition to adulthood. It seems particularly important to understand parents' views of these relational issues if they have been anticipating the day when their "nest" would empty (Hagestad, 1984).

The transition to adulthood has been described as the stage of life marked by significant "age inflation" (Vobejda, 1991). In light of changing demographics and economic conditions in the United States, we may need to revise the developmental timetable for independence, rethink assumptions about the process, and describe several different paths that parents and children may take as they restructure the ties that bind them. If "leaving home" is no longer the normal imperative of late adolescence, we will need to pay more attention to the opportunities and constraints that different developmental contexts offer during the adolescent to adult transition.

\section{APPENDIX}

Late Adolescents' Relationships With Parents (LARP)

\section{Mutuality}

I confide in my parent(s) about things that concern me.

My parent(s) take my ideas seriously.

I respect my parents' opinions even when we disagree.

My parent(s) are interested in hearing my ideas and opinions.

Even though my parent(s) disagree with me, they respect my right to my own opinion.

\section{Enabling Independence}

I make my own decisions about things that affect me.

My parent(s) expect me to take responsibility for my actions.

I feel that I control my life.

My parent(s) encourage me to be independent.

\section{Support}

My parent(s) care about me and I know I can rely on them.

I like my parents as people despite their faults and shortcomings.

I can rely on my parent(s) whenever I need help. 
My parent(s) are a source of embarrassment for me. (R) I know that my parent(s) will always "be there" for me.

\section{Rejection of Parents as Role Models}

There are things that $I$ will do differently from my mother and father when I become a parent.

When I become a parent, I'm going to treat my children in exactly the same way that my parent(s) have treated me. (R).

I hate to think that I might become like my parent(s) one day.

\section{Avoidance}

My parent(s) end arguments with me by walking away or hanging up the telephone.

I end arguments with my parent(s) by walking away or hanging up the telephone.

The best way for me to handle differences of opinion with my parent(s) is not to discuss the issue.

If I disagree with my parent(s) on some issue, they refuse to discuss it.

\section{Parental Underestimation of Maturity Demands}

My parent(s) act like I'm still in high school.

My parent(s) don't realize how hard college is.

My parent(s) don't seem to realize how many responsibilities I have.

My parent(s) feel that I'm unaware of the "real" world.

My parent(s) seem to think that college is pretty much like high school.

\section{ACKNOWLEDGMENTS}

We would like to thank Rob Hymes, Joan Jurich, Laura Gillespie, Linda Pente, and Pranau Shaw for their assistance in this project.

\section{REFERENCES}

Bell, D. C, and Bell, L. G. (1983). Parental validation and support in the development of adolescent daughters. In Grotevant, H. D., and Cooper, C. R. (eds.), Adolesceni Development in the Family. New Directions for Child Development. Jossey-Bass, San Francisco. 
Berman, W. H., and Sperling, M. B. (1991). Parental attachment and emotional distress in the transition to college. J. Youth Adolesc. 20: 427-440.

Blos, P. (1979). The Adolescent Passage. International Universities Press, New York.

Campbell, E., Adams, G. R., and Dobson, W. R. (1984). Familial correlates of identity formation in late adolescence: A study of the predictive utility of connectedness and individuality in family relations. $J$. Youth Adolesc. 13: 509-525.

Cantor, N., Norem, J. K., Niedenthal, P. M., Langston, C. A., and Brower, A. M. (1987). Life tasks, self-concept ideals, and cognitive strategies in a life transition. J. Personal. Social Psychol. 53: 1178-1191.

Cattell, R. B. (1966). The scree test for the number of factors. Multivariate Behav. Res. 1: 245-276.

Clemens, A. W., and Axelson, L. J. (1985). The not-so-empty nest: The return of the fledgling adult. Family Relat. 34: 259-264.

Compas, B. E., Wagner, B. M., Slavin, L. A., and Vannatta, K. (1986). A prospective study of life events, social support, and psychological symptomatology during the transition from high school to college. Am. J. Commun. Psychol. 14: 241-257.

Cooper, C. R., Grotevant, H. D., and Condon, S. M. (1983). Individuality and connectedness in the family as a context for adolescent identity formation and role taking skill. In Grotevant, H. D., and Cooper, C. R. (eds.), Adolescent Development in the Family. New Directions for Child Development. Jossey-Bass, San Francisco.

Demo, D. H. (1991). A sociological perspective on parent-adolescent disagreements. In PaiKoff, R. L. (ed.), Shared Views in the Family During Adolescence. New Directions for Child Development. Jossey-Bass, San Francisco.

DeSantis, J., and O'Brien, R. W. (1992, March). Multiple perceptions of parent-child individuation during adolescence: The role of behavior interventions by parents. Poster presented at the Society for Research on Adolescence Biennial Meeting, Washington, DC.

The Forgotten Half: Pathways to Success for America's Youth and Young Families. (1988). Youth and America's Future: The William T. Grant commission on work, Family, and Citizenship, Washington, DC.

Frank, S. J., Avery, C. B., and Laman, M. S. (1988). Late adolescents' perceptions of their relationships with their parents: Individual differences in connectedness, competence, and emotional autonomy. Develop. Psychol. 24: 729-737.

Frank, S. J., Pirsch, L. A., and Wright, V. C. (1990). Late adolescents' perceptions of their relationships with their parents: Relationships among deidealization, autonomy, relatedness, and insecurity and implications for adolescent adjustment and ego identity status. J. Youth Adolesc. 19: 571-588.

Franz, C. E., and White, K. M. (1985). Individuation and attachment in personality development: Extending Erikson's theory. J. Personal. 53: 224-256.

Glick, P. C., and Lin, S. L. (1986). Young adults living with parents. J. Marriage Family 44: 63-72.

Gorsuch, R. L. (1983). Factor Analysis (2nd ed.). Lawrence Erlbaum Associates, Hilisdale, NJ.

Gould, R. L. (1978). Transformations: Growth and Change in Adult Life. Simon \& Schuster, New York.

Grotevant, H. D., and Cooper, C. R. (1985). Patterns of interaction in family relationships and the development of identity exploration in adolescence. Child Develop. 56: 415-428.

Grotevant, H. D., and Cooper, C. R. (1986). Individuation in family relationships: A perspective on individual differences in the development of identity and role-taking skill in adolescence. Human Develop. 29: 82-100.

Hagestad, G. O. (1984). The continuous bond. In Perlmutter, M. (ed.), Minnesota Symposia on Child Psychology, (Vol. 17). Lawrence Erlbaum Associates, Hillsdale, NJ.

Hamilton, S., and Fagot, B. I. (1988). Chronic stress and coping styles: A comparison of male and female undergraduates. J. Personal. Social Psychol. 55: 819-82்̇.

Hill, J. P., and Holmbeck, G. N. (1986). Attachment and autonomy during adolescence. Ann. Child Develop. 3: 145-189. 
Kidwell, S. (1992, March). Family factors in the prediction of college adjustment. Poster presented at the Society for Research on Adolescence Biennial Meeting, Washington, DC.

Lempers, J. D., and Clark-Lempers, D. S. (1992). Young, middle, and late adolescents' comparisons of the functional importance of five significant relationships. J. Youth Adolesc. 21: $53-96$

Levinson, D. (1986). A conception of adult development. Am. Psychol. 41: 3-13.

Montemayor, R., and Hanson, E. (1985). A naturalistic view of conflict between adolescents and their parents and siblings. J. Early Adolesc. 5: 23-30.

Moore, D. (1987). Parent-adolescent separation: The construction of adulthood by late adolescents. Develop. Psychol. 23: 298-307.

Offer, D., and Offer, J. B. (1975). From Teenage to Young Manhood: A Psychological Study. Basic Books, New York.

O'Brien, R. W., DeSantis, J. P., and Santilli, N. (1988, November). Construction of a measure of adolescent individuation. Poster presented at the Virginia Developmental Forum, Randolph Macon College, Ashland, VA.

Paul, E. L. (1992, March). Parent-child relationships in the transition from late adolescence to young adulthood. Poster presented at the Society for Research on Adolescence Biennial Meeting, Washington, DC.

Roberts, P., and Newton, P. M. (1987). Levinsonian studies of women's adult development. Psychol. Aging 2: 154-163.

Ryan, R. M., and Lynch, J. H. (1989). Emotional autonomy versus detachment: Revisiting the vicissitudes of adolescence and young adulthood. Child Develop. 60:340-356.

Shantz, C. U., and Hobart, C. J. (1989). Social conflict and development. In Berndt, T. J., and Ladd, G. W. (eds.), Peer Relationships in Child Development. Wiley, New York.

Steinberg, L., and Lamborn, S. (1992, March). Autonomy redux: Adolescent adjustment as a joint function of emotional autonomy and relationship security. Paper presented at the Society for Research on Adolescence Biennial Meeting, Washington, DC.

Sullivan, K., and Sullivan, A. (1980). Adolescent-parent separation. Develop. Psychol. 16: 93-99.

Vobejda, B. (1991, September 23-29). Declarations of Dependence: It's taking longer to become on adult. The Washington Post National Weekly Edition, pp. 9-10.

White, K. M., Spiesman, J. C., and Costos, D. (1983). Young adults and their parents: Individuation to Acceptance. In Grotevant, H. D., and Cooper, C. R. (eds.), Adolescent Development in the Family. New Directions for Child Development. Jossey-Bass, San Francisco.

White, K. M., Spiesman, J. C., Costos, D., and Smith, A. (1987). Relationship maturity: A conceptual and empirical approach. Contrib. Human Develop. 18: 81-101.

Youniss, J. (1983). Social construction of adolescence by adolescents and parents. In Grotevant, H. D., and Cooper, C. R. (eds.), Adolescent Development in the Family. New Directions for Child Development. Jossey-Bass, San Francisco.

Youniss, J., and Smollar, J. (1985). Adolescent Relations with Mothers, Fathers, and Peers. University of Chicago Press, Chicago. 